\title{
Monitoring the Level of Antibiotic Purchase without a Prescription among Libyan Young Adults
}

\author{
Ahmed Atia \\ Department of Anesthesia and Intensive Care, Faculty of Medical Technology, Tripoli University, Tripoli, Libya.
}

\begin{abstract}
Antibiotics are typically prescription only medicines. A high percentage of world's antibiotics are sold without prescription by health-care specialists. The study assessed use of antibiotics without prescription among young adults in Libya. A pre-tested questionnaire was designed to evaluate reported name and utilization of antibiotics without prescription. Of 610 participants approached, 582 decided to contribute in this study, giving a response rate of $95.4 \%$. 56.19\% respondents conveyed acquisition of an antibiotic without a prescription. Only $21.1 \%$ correctly named an antibiotic as the medicine obtained. Among the survey participants who utilized an antibiotic without a prescription, $98.1 \%$ used antibiotic for insufficient period ( $<3$ days) or at inappropriate dosing intervals. The most frequently named antibiotic bought without a prescription is Augmentin ${ }^{\circledR}$. An attention of health care policy makers should be focused on physicians and pharmacists, as the main information providers of rational antibiotic use, as well as on community pharmacies, identified as the main source of non-prescription antibiotics.
\end{abstract}

Key words: Antibiotics, Self-medication, Prescription, Young Adult, Libya.

\section{INTRODUCTION}

Indiscriminate use of antibiotics is a globally significant health challenge. Antibiotics, one of the most crucial medical successes, are becoming less effective due to unsuitable use. Bacteria are progressively becoming resistant to antibiotics and resistant bacteria have spread globally, representing that we may be at the beginning of a post-antibiotics period. Inappropriate use of antibiotics, include failure to complete therapy, skipping of doses or reuse of leftover antibiotics, can potentially rendering patients to improper doses of antibiotic therapy. Lacking knowledge, alertness, and patient education regarding the utilization of antibiotics by the healthcare providers are among predisposing factors for the development of such resistance. ${ }^{1-4}$ Although resistance is frequently reported in Europe and North America, developing countries also face the issue of antimicrobial resistance. ${ }^{5,6}$ The concern of antibiotic resistance has been labelled as a significant public health challenge in a World Health Organization report (WHO), 2007. ${ }^{7}$ Rendering to WHO global strategy for diminish antimicrobial resistance, regardless of the ability to stay ahead of the pathogens by development and reform of novel drug in the 1950s and 1980 s, the existing situation is not promising. Hence, the rational use of the antibiotics and patient education is essential. ${ }^{7}$ Addressing the problem of the development of resistance and inappropriate use of antibiotics has become a global effort in recent years. In 2016, the United Nation general assembly held a critical summit on antimicrobial resistance and approved a declaration of international cooperation in fighting the issue of antibiotics resistant. ${ }^{8}$ The concern of antibiotic resistance was also of great importance in the agenda of the Group of Seven (G7) and the Group of Twenty (G20). ${ }^{9}$

In many developed countries, the accessibility of antibiotics is strictly striped by insisting that no antibiotics are distributed without written prescription by physician or dispensed by pharmacists. ${ }^{10}$ However, in other countries around the world antibiotics are sold without prescription. ${ }^{11}$ In Europe, the occurrence of antibiotic resistance
DOI: 10.5530/ijopp.11.4.43

Address for correspondence: Ahmed Atia, Department of anesthesia and intensive care, faculty of Medical technology, Tripoli University, Tripoli, Libya.

Phone no: 00218921132362

Email Id: elbadri83@yahoo.com

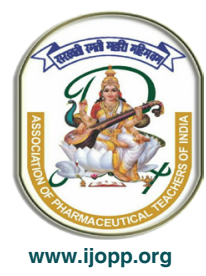


differs among different countries and such incidence not only depends upon the absence of knowledge and alertness towards the development of resistant strain of bacteria but also depend upon unsuitable drug usage policy in the countries. ${ }^{12}$ Antibiotics self-medication is currently at an alarming level in Libya. ${ }^{13}$ Libya carries a high burden of infectious diseases and consequently has a high antibiotics usages. ${ }^{14}$ The antibiotic prescriptions in Libya are not controlled by any policy, and there are no clear guidelines in this regard..$^{15}$ No matter how or where the public gain access to these essential groups of medicines, it is an issue that must be explored and mandates necessary interventions.

\section{Purpose of study}

The current study set out to explore prevalence of antibiotics self-medication and suitability of use among young adults in Tripoli city of Libya.

\section{METHODS}

A questionnaire was designed to assess level of reported use of antibiotics without prescriptions. The questions assessed facts on the exercise of using antibiotics as self-administration, as well as perception of respondents toward antibiotics. The questionnaire was written in English (Translated verbally to the local language) and was pre-validated on a sample of 20 students and comments were taken into consideration. A total of 610 questionnaires were distributed.

\section{Statistical analysis}

Data were analyzed by SPSS software using descriptive statistics.

\section{RESULTS}

Out of 610 questionnaires distributed, a total of 582 (95.4\%) were completed and returned. The majority of students $(414,71.13 \%)$ were females, and the mean age for respondents was $27 \pm 0.68$ years. A high Level of purchase antibiotic without a prescription was reported. Antibiotics were obtained with a medical prescription by $43.81 \%(\mathrm{n}=255)$ and used for self-medication without prescription by $56.19 \%(\mathrm{n}=327)$ of students (Figure 1). Among the surveyed participants who reported use of antibiotics as self-medication, only 6 out of 327 respondents $(1.8 \%)$ used antibiotics for $>3$ days showing that $98.2 \%$ of respondents that obtained antibiotics without prescription did not use it correctly. The most frequently named antibiotics obtained by respondents

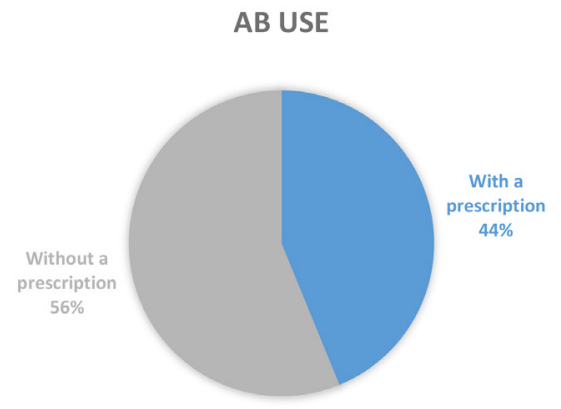

Figure 1: Level of purchase antibiotic with or without a prescription.

Table 1: Names of drugs purchased without prescription.

\begin{tabular}{ccc}
\hline Drug & Respondents $(\mathbf{n})$ & \% Percentage \\
\hline Co-amoxiclav & 120 & 61.8 \\
Amoxicillin & 51 & 26.3 \\
Cephalosporins & 13 & 6.7 \\
Tetracycline & 3 & 1.6 \\
Metronidazole & 7 & 3.6 \\
Total & 194 & 100 \\
\hline
\end{tabular}

without a prescription was Augment ${ }^{\circledR}$. It was purchased by 120 out of the 194 respondents (that is, $61.8 \%$ ) followed by Amoxicillin 26.3\% (Table 1).

\section{DISCUSSION}

The work investigated the use of antibiotics without prescription among young adults in Libya. It assessed the level of misuse of these agents in the community. Out of 610 questionnaires distributed, 582 (95.4\%) were completed and returned. A high Level of antibiotic acquisition without a prescription was conveyed, with Augmentin ${ }^{\circledR}$ being the most frequently named antibiotics obtained by respondents without a prescription $(61.8 \%)$, followed by Amoxicillin 26.3\%.

The International Pharmaceutical Federation (FIP) announcement of strategy control on antimicrobial drugs resistance as well as WHO international policy for regulation of antibiotic resistance stresses the state members to promote educational and alertness campaign in response to antimicrobial resistance. ${ }^{16}$ In order to adapt proper actions to fight against antibiotic resistance as a response to these recommendations, the assessment of knowledge about antibiotics and the factors influencing the purchase of antibiotic as self-medication among Libyan population is thus crucial. Although the prevalence of antibiotic use without prescription has frequently been reported in other countries, few published studies have 
addressed the problem in Libya. ${ }^{11,17-20}$ In the current study, $56.19 \%$ of young adults surveyed have purchased an antibiotic without prescription. The result is comparable to study conducted in Iran $53 \%,{ }^{21}$ but higher than study conducted in Benghazi city of Libya which reported level of purchase of antibiotic for self-medication at $29 \%$, while purchase of antibiotics without a prescription in a survey of Jordanian youths was $38 \% .^{19,22}$ In contrast, a study conducted amongst the Greek population reported higher level of non-prescribed antibiotic of $74.6 \%{ }^{23}$ This inconsistency in findings may be attributed to variance in age group surveyed, as the previous studies seem to have studied population constituting of older adults. This perhaps suggests that use of antibiotic without prescription is a practice that increases with age of the population if left unrestricted.

The most frequently antimicrobial used self-medications in our study was Augmentin ${ }^{\circledR}$. This is closely in line with earlier reported study that stated Augmentin's with extended spectrum to have the as highest percentage for self-medication in treating upper respiratory infection, ${ }^{11}$ and the recent Indian study that revealed Augmentin was the most commonly purchased antibiotic without prescription. ${ }^{24} \mathrm{It}$ is becoming necessary that purchases of antibiotics need to be controlled in our environment to avert unsuitable use of antibiotics and slow antimicrobial resistance progression. Self-medication of antibiotic defined as the use of antibiotics without a prescription and the reported use of improper dose and insufficient duration was revealed to be high $56.19 \%$ among our population sample. A previous work also documented some measure of unsuitable use of antibiotic without prescription, ranging from 35\% (those with inappropriate therapy period) to $41.6 \%$ (those that discontinued therapy earlier than suitable time). ${ }^{25}$

\section{Strengths and Limitations}

The findings of the current study emphasized on the need to improve basic knowledge of antibiotics in our community. As with all self-reported records the outcomes of this survey may have the potential for recall bias. While this study was to evaluate the practice use of antibiotics by young adults in our regional community, the results of this study cannot be generalized to other settings and populations, since this was a study conducted in a specific region and a young population.

\section{ETHICAL CONSIDERATION}

The study was ethically approved by Scientific Committee of Faculty of Medical Technology, Tripoli University, Libya.

\section{ACKNOWLEDGEMENT}

We are grateful for all the respondents who contributed in this study.

\section{CONFLICT OF INTEREST}

The author declared no conflict of interest

\section{ABBREVIATIONS}

WHO: World Health Organization, G7: Group of Seven, G20: Group of Twenty, SPSS: Statistical Package for the Social Sciences, FIP: International Pharmaceutical Federation.

\section{REFERENCES}

1. Hassali MA, Arief M, Saleem F, Khan MU, Ahmad A, Mariam W et al. Assessment of attitudes and practices of young Malaysian adults about antibiotics use: a cross-sectional study. Pharmacy Practice. 2017;15(2):929.

2. Wang X, Lin L, Xuan Z, Li L, Zhou X. Keeping Antibiotics at Home Promotes Self-Medication with Antibiotics among Chinese University Students. Int J Environ Res Public Health. 2018:15(4):687.

3. Erku DA, Mekuria AB, Belachew SA. Inappropriate use of antibiotics among communities of Gondar town, Ethiopia: a threat to the development of antimicrobial resistance. Antimicrobial Resistance and Infection Control. 2017;6(1):112.

4. Gebeyehu E, Bantie L, Azage M. Inappropriate Use of Antibiotics and Its Associated Factors among Urban and Rural Communities of Bahir Dar City Administration, Northwest Ethiopia. PLoS One. 2015;10(9): e0138179.

5. Da Costa ME, Machado HS. Evolution of Antimicrobial Resistance in Europe: A Factual Review. J Allergy Ther. 2017;8:250.

6. Almagor J, Temkin E, Benenson I, Fallach N, Carmeli Y. The impact of antibiotic use on transmission of resistant bacteria in hospitals: Insights from an agentbased model. PLoS ONE. 2018;13(5):e0197111.

7. World Health Organization. The world health report Switzerland: World Health Organization; 2007.

8. Genral Assembly of the United Nations. Available online: http://www.un.org/ pga/71/event-latest/highlevel-meeting-on-antimicrobial-resistance/ (accessed on 11 Aug 2018).

9. Inoue H, Minghui R. Antimicrobial resistance: Translating political commitment into national action. Bull. World Health Organ. 2017;95(4):242.

10. Xiao Y, Zhang J, Zheng B et al. Changes in Chinese policies to promote the rational use of antibiotics. PLoS Med. 2013; 10: e1001556.

11. Atia AE, Abired AN. Antibiotic prescribing for upper respiratory tract infections by Libyan community pharmacists and medical practitioners: An observational study. Libyan J Med Sci. 2017;1(2):31-5.

12. Bjerrum L, Boada A, Cots JM, Llor C, Forés Garcia D, Gahrn-Hansen B et al. Respiratory tract infections in general practice: considerable differences in prescribing habits between general practitioners in Denmark and Spain. Eur J Clin Pharmacol. 2004;60(1):23-8.

13. Elsayah K, Atia A, Bkhait N. Antimicrobial resistance pattern of bacteria isolated from patients with urinary tract infection in Tripoli city, Libya. Asian J Pharm Hea Sci. 2017;7(4):1751-5.

14. GPCHE: Annual Statistical and Health Report, MOH/HIS; 2010.

15. Elmehdawi R, Albarsha A. Pattern of antibiotic prescription to hospitalized patients in a teaching hospital in Benghazi-Libya. Libyan J Infect Dis. 2008;2:29-34.

16. The Hague: International Pharmaceutical Federation. FIP Statement of Policy Control of Antimicrobial Medicines Resistance (AMR). Available from: http:// apps.who.int/medicinedocs/en/d/Js19755en/ (accessed 12 Aug 2018).

Indian Journal of Pharmacy Practice, Vol 11, Issue 4, Oct-Dec, 2018 
17. Ghenghesh K, Rahouma A, Tawil K, Zorgani A, Franka E. Antimicrobial resistance in Libya: 1970-2011, Libyan Journal of Medicine. 2013;8(1):20567.

18. Scicluna EA, Borg MA, Gür D, Rasslan O, Taher I, Redjeb SB et al. Self-medication with antibiotics in the ambulatory care setting within the Euro-Mediterranean region; results from the ARMed project. J Infect Public Health. 2009;2(4):189-97.

19. Ghaieth MF, Elhag SR, Hussien ME, Konozy EH. Antibiotics self-medication among medical and nonmedical students at two prominent universities in Benghazi city, Libya. J Pharm Bioallied Sci. 2015;7(2):109-15.

20. Bukhatwa S, Trabelsi S, Abduelmula A, Elfakhr M. Antibiotics Misuse in Libya: Observational Study; Available from: http://uob.edu.ly/assets/uploads/ pagedownloads/53566-abstrac525t.pdf. (Last accessed on 12 Aug 2018).

21. Askarian M, Maharlouie N. Irrational antibiotic use among secondary school teachers and university faculty members in Shiraz. Iran. Int J Prev Med. 2012;3(12):839-45.
22. Yusef D, Babaa A, Bashaireh A, Al-Bawayeh H, Al-Rijjal K, Nedal M et al. Knowledge, practices \& attitude toward antibiotics use and bacterial resistance in Jordan: A cross-sectional study. Infection, Disease \& Health. 2018;23(1):3340.

23. Mitsi G, Jelastopulu E, Basiaris H, Skoutelis A, Gogos C. Patterns of antibiotic use among adults and parents in the community: a questionnaire based survey in a Greek Urban population. Int. J. Antimicrob. Agents. 2005;25(5):439-43.

24. Saleem Z, Saeed H, Ahmad M et al. Antibiotic Self-Prescribing Trends, Experiences and Attitudes in Upper Respiratory Tract Infection among Pharmacy and Non-Pharmacy Students: A Study from Lahore. Sambhara S, ed. PLoS ONE. 2016;11(2):e0149929.

25. Atia A, Ashour A, Abired A. Survey on knowledge towards antibiotics among medical university students in Libya. Int J MediPharm Res. 2018;4(2):61-6. 